\title{
Effects of Processing on Antioxidant Capacity and Metabolizing Enzyme Inhibition of Tiger Nut Tubers
}

\author{
Shantrell Willis, Cydney Jackson, Martha Verghese* \\ Department of Food and Animal Sciences, Alabama Agricultural and Mechanical University, Normal, AL, USA \\ Email: *Martha.verghese@aamu.edu
}

How to cite this paper: Willis, S., Jackson, C. and Verghese, M. (2019) Effects of Processing on Antioxidant Capacity and Metabolizing Enzyme Inhibition of Tiger Nut Tubers. Food and Nutrition Sciences, 10, 1132-1141.

https://doi.org/10.4236/fns.2019.109082

Received: July 2, 2019

Accepted: September 24, 2019

Published: September 27, 2019

Copyright $\odot 2019$ by author(s) and Scientific Research Publishing Inc. This work is licensed under the Creative Commons Attribution International License (CC BY 4.0).

http://creativecommons.org/licenses/by/4.0/

\begin{abstract}
Tiger nut (Cyperus esculentus), commonly referred to as chufa, is a "nut-like" tuber, native to tropical and Mediterranean regions. It is often consumed in the form of a beverage (horchata de chufa). Health benefits of tiger nut have been attributed to presence of phytochemicals and their antioxidant potential. Tiger nut is often processed in order to enhance sensory characteristics. The objective of study was to determine effects of processing on antioxidant content, potential and inhibition of metabolizing enzyme activities of tiger nuts. Total phenolic content (TPC), total flavonoid content (TFC), free radical scavenging activity by 1,1-diphenyl-2-picryhydrazyl (DPPH), trolox equivalent antioxidant capacity (TEAC), ferric reducing antioxidant power (FRAP) and inhibition of lipase and $\alpha$-amylase were evaluated in raw tiger nuts extracted with water (TRWA) and methanol (TRWM) and roasted $\left(110^{\circ} \mathrm{C}-115^{\circ} \mathrm{C}\right.$ for 10 mins) tiger nuts extracted with water (TRA) and methanol (TRM). Highest phenolic content was observed in TRWA (1186.68 GAE/100g) and TRWM had lowest (43.77 GAE/100g). TRWA also exhibited highest ferric reducing ability with a FRAP value of $169.83 \mathrm{~mm} \mathrm{Fe} 2+100 \mathrm{~g})$. TRWM had a higher flavonoid content $(220.68 \mathrm{CAE} / 100 \mathrm{~g})$ compared to all other extracts. At a concentration of $0.02 \mathrm{mg} / \mathrm{ml}$, all extracts reached at least $50 \%$ inhibition of DPPH, while highest scavenging activity was observed in TRM (58\%). Highest TEAC was observed in TRM with $55.66 \%$ of ABTS radical scavenged. TRA had a significantly higher ability to inhibit $\alpha$-amylase and lipase compared to other extracts. Results suggest that processing had an effect on the antioxidant potential of tiger nut, and this tuber may benefit consumers by improving their antioxidant status.
\end{abstract}

\section{Keywords}

Antioxidant, Tuber, Enzyme 


\section{Introduction}

Oxidative stress is a main influencer of a number of chronic disease pathologies, including cancer, diabetes and obesity [1] [2] [3]. Antioxidants help to lessen the effects of oxidative stress, by neutralizing free radicals [4]. Natural antioxidants are receiving an enormous amount of attention from nutritionists, food manufacturers, medical experts and consumers due to their health benefits.

Research suggests fruits and vegetables have various beneficial effects on health, which may be attributed to phytochemicals present [5]. One such group of vegetables includes starchy tuber crops. Starchy tubers are a prominent source of carbohydrates, worldwide, second to cereals [6]. Tubers have shown to be a source of various macro- and micronutrients that are crucial to the body, including, protein, calcium, and vitamin C [7]. One tuber that is increasing in popularity is the tiger nut.

Tiger nut (Cyperus esculentus), also commonly referred to as chufa, is a "nut like" tuber native to tropical and Mediterranean regions. Though tiger nut is often consumed as a beverage (horchata de chufa) and is utilized in animal feed [8], it is still considered an underutilized crop. Tiger nut has purported health benefits when consumed. Research has shown that the consumption of tiger nut may prevent heart disease, as well as exhibit antithrombotic and colon cancer reducing abilities [9] [10]. These beneficial properties may be linked to the presence of potassium, phosphorous, ascorbic acid, $\alpha$-tocopherol and other antioxidative phytochemicals [11].

Due to the high amounts of carbohydrates and lipids, the western diet has been associated with the promotion of diseases of civilization, including obesity and diabetes [12]. Lipase and $\alpha$-amylase are enzymes that aid in the metabolism of fats (lipase) and carbohydrates ( $\alpha$-amylase). Pancreatic lipase, composed of 449 amino acids, is a crucial enzyme for the absorption of dietary triglycerides [13]. $\alpha$-amylase (pancreas) is an enzyme that plays a key role in carbohydrate digestion. The inhibition of these key metabolizing enzymes could result in retardation of lipid and carbohydrate absorption; possibly reducing the risk of chronic diseases [14] [15]. Though limited research has been conducted on tiger nut's effect on obesity and diabetes, some studies do suggest the effects of other tubers on the aforementioned health conditions. A study conducted by Mahadita and others shows that purple sweet potato extract may improve glycemic control in type II diabetes patients [16]. The possible anti-obesity effects of another tuber, Kedrostis africana, were suggested in research conducted by Unuofin and others via the inhibition of the fat metabolizing enzyme, lipase [17].

Research suggests that processing or thermal treatment of plant substances could increase, decrease or exert no change on antioxidant capacity [18] [19]. The effect of processing on tiger nut was explored in the current study, as tiger nut is not commonly consumed raw, due to unfavorable sensory traits. Roasting of tiger nut decreased levels of anti-nutritive compounds in a previous study [9]. 
To date, there has been some research conducted on the phytochemical content and potential health benefits of tiger nut, but there has been limited research considering the effects of processing on antioxidative and metabolizing enzyme activities. The incorporation of natural antioxidants and functional carbohydrates into the diet is increasing. Because of this, there is a possible niche in the market for underutilized tuber crops. Though there are some products containing starchy tuber crops on the market, there is still a need to incorporate products from different plant sources and investigate their antioxidant properties. The objective of the current study was to determine effects of processing on antioxidant content, potential and inhibition of metabolizing enzyme activities of raw and roasted tiger nuts.

\section{Materials and Methods}

All chemicals were obtained from Sigma Chemical Company, St. Louis, Mo. and Fisher Scientific Company, Waltham, Mass. Tiger nut tubers were obtained from Organic Gemini, Brooklyn, NY.

\subsection{Determination of Phytochemicals in Tiger Nut Tubers}

Sample preparation and extraction of phenolics: Extraction of tiger nut tubers was performed using established methods. Tiger nut tubers were extracted raw (unprocessed control) and roasted (processed). Roasted tubers were exposed to heat $\left(110^{\circ} \mathrm{C}-115^{\circ} \mathrm{C}\right)$ for 10 mins. Both raw and roasted tubers were ground to a powder using a Robot Coupe Blixer $4 \mathrm{~V}$ (Ridgeland, MS). Five grams of tuber powder was added to $50 \mathrm{~mL}$ of methanol $(80 \%)$, or water $\left(25^{\circ} \mathrm{C}\right)$. The mixtures were stirred for $2 \mathrm{hr}$ on an orbital shaker then centrifuged at $3000 \times \mathrm{g}$ for 20 mins. The supernatant was collected, filtered, and evaporated to dryness. The extraction was reconstituted with respective solvent and stored at $-80^{\circ} \mathrm{C}$ until further analysis. Tiger nut extracts were identified as follows: TRWA (tiger nut raw extracted with water); TRWM (tiger nut raw extracted with $80 \%$ methanol); TRA (tiger nut roasted extracted with water); TRM (tiger nut roasted extracted with $80 \%$ methanol).

Determination of Total Phenolic and Total Flavonoid Contents in Tiger Nut Extracts. Total phenolics in tuber extracts were determined by the Folin-Ciocalteau method and reported as gallic acid equivalents (GAE) as described by [20]. Total flavonoids in tiger nut tuber extracts were determined by a colorimetric methods described by [20] and reported as catech in equivalents (CAE).

\subsection{Antioxidant Potential of Tiger Nut}

Antioxidant activities including, ferric reducing antioxidant power (FRAP), 1,1 diphenyl 2-picrahydrazyl (DPPH) radical scavenging ability, and trolox equivalent antioxidant capacity (TEAC).

FRAP of tiger nut extracts was determined by the methods described by [21]. 
DPPH radical scavenging ability of tuber extracts was determined following methods described [20].

Trolox equivalent antioxidant capacity (TEAC) of tiger nut extracts was performed following methods by [22] using the 2,2'-azino-bis(3-ethylbenzothiazoline-6-sulfonic acid (ABTS) radical.

\subsection{Determination of Lipid and Carbohydrate Metabolizing Enzyme Inhibition}

Inhibition of lipase and $\alpha$-amylase by tiger nut extract was determined by methods described by [23] and [24], respectively.

\subsection{Statistical Analysis}

Results are presented as means \pm SEM using SAS system version 9.3 ANOVA was used to determine any significant differences among the treatment groups. Significance was determined at $\mathrm{p} \leq 0.05$. The means were separated using $\mathrm{Tu}$ key's Studentized Range Test.

\section{Results and Discussion}

There are a number of products on the market currently that incorporate tubers, yet tiger nut (tuber) is an underutilized crop that may have functional properties. The effects of processing on antioxidant content, potential and metabolizing enzyme activities of tiger nut tuber extracted with water and methanol was determined. Figure 1 shows the total phenolic content of raw and roasted tiger nut tuber extracted with methanol and water. Overall, tiger nut (raw and roasted) extracted with water had a significantly $(\mathrm{p} \leq 0.05)$ higher content compared to TRWM and TRM. Water was able to extract more phenolic compounds from tubers compared to organic solvent; suggesting the presence of more water-soluble phytochemicals in the substance. Roasted significantly $(\mathrm{p} \leq 0.05)$ increased phenolic yield in methanolic extracts.

Figure 2(a) shows the total flavonoid content of TRWA, TRWM, TRA and TRM. Roasting, followed by aqueous extraction, significantly $(\mathrm{p} \leq 0.05)$ decreased flavonoid content yield compared to other extracts. DPPH results are displayed in Figure 2(b). DPPH is a stable free radical that is deep purple in color. This assay measures the ability of biological samples to reduce 1,1-diphenyl-2-picryl hydrazyl radical to 1,1-diphenyl-2-picryl hydrazine [25], therefore a reduction in purple color indicates a reduction in free radicals. Though all extracts showed at least $50 \%$ (extract concentration $0.02 \mathrm{mg} / \mathrm{ml}$ ) percent inhibition, neither processing nor solvent extraction had an effect on the tiger nut tuber's ability to scavenging the DPPH free radical.

Figure 3 displays the ferric reducing antioxidant power of raw and roasted tiger nut extracts. The ability of the tuber to reduce ferric to ferrous iron is displayed here, but neither processing nor solvent extraction had an effect on the reducing ability. 




Figure 1. Total phenolic content of tiger nut extracts. Bars $(n=3)$ expressed as means \pm SEM. Means within treatments without a common letter ${ }^{(\mathrm{abc})}$ differ significantly at $\mathrm{p} \leq$ 0.05. Abbreviations: GAE—gallic acid equivalents, TRWA-tiger nut raw extracted with water, TRWM-tiger nut raw extracted with $80 \%$ methanol, TRA-Tiger nut roasted extracted with water, TRM-tiger nut roasted extracted with $80 \%$ methanol.

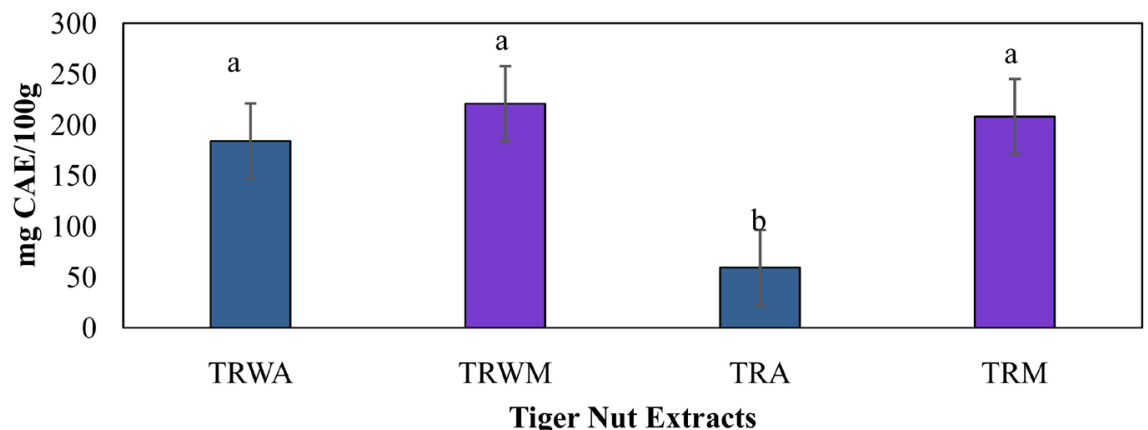

(a)



(b)

Figure 2. Total flavonoid content and dpph radical scavenging of tiger nut extracts. Bars $(\mathrm{n}=3)$ expressed as means \pm SEM. Means within treatments without a common letter ${ }^{(\mathrm{abc})}$ differ significantly at $\mathrm{p} \leq 0.05$. Abbreviations: CAE-catech in equivalents, DPPH1,1-diphenyl, 2-picrahydrazyl, TRWA-tiger nut raw extracted with water, TRWMtiger nut raw extracted with $80 \%$ methanol, TRA-Tiger nut roasted extracted with water, TRM-tiger nut roasted extracted with $80 \%$ methanol.

TEAC of tiger nut extracts, reported as trolox equivalents (TE)/g of sample, is displayed in Figure 4. Trolox is a water-soluble analog of vitamin E; this assay compares the ability of the tiger nut extracts to scavenge the ABTS radical (ABTS+ to ABTS-) [22] to that of vitamin E. There were no significant ( $\mathrm{p} \leq$ 0.05) differences in TEAC among TRWA, TRWM, TRA and TRM. 


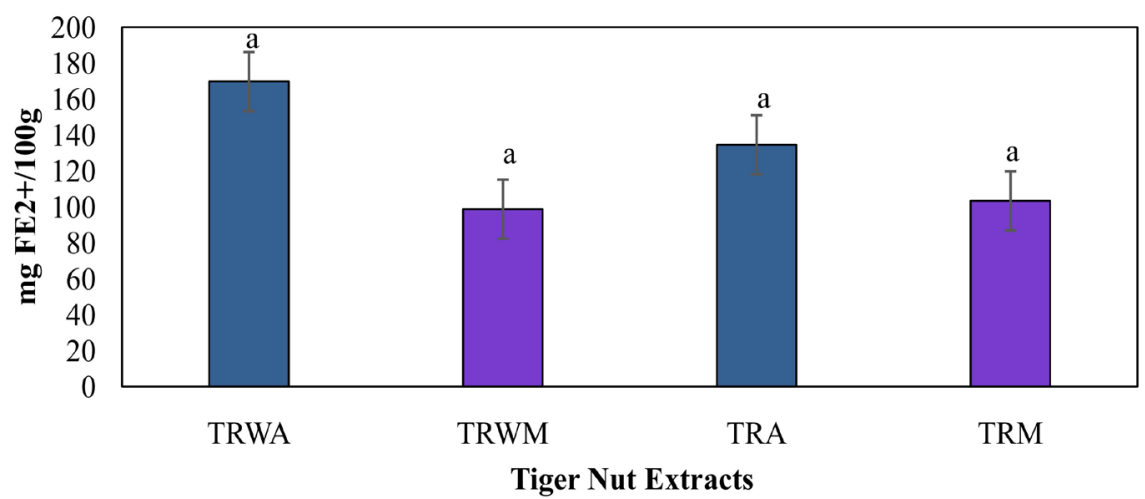

Figure 3. Ferric Reducing antioxidant power of tiger nut extracts. Bars ( $n=3)$ expressed as means \pm SEM. Means within treatments without a common letter ${ }^{\text {(abc) }}$ differ significantly at $\mathrm{p} \leq 0.05$. Abbreviations: $\mathrm{FE}^{2+}-$ Ferrous sulphate, TRWA-tiger nut raw extracted with water, TRWM-tiger nut raw extracted with $80 \%$ methanol, TRA-Tiger nut roasted extracted with water, TRM-tiger nut roasted extracted with $80 \%$ methanol.

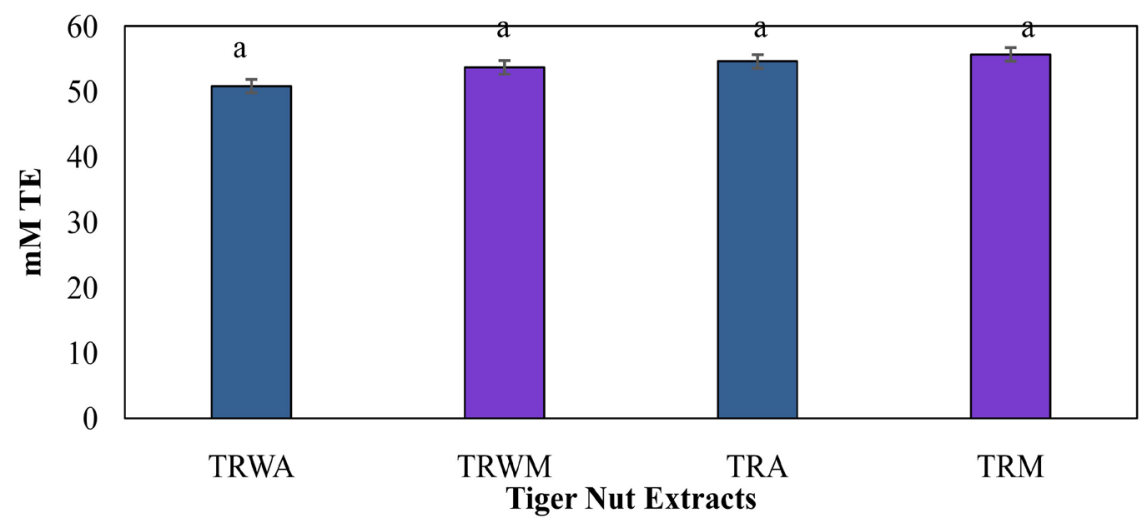

Figure 4. Trolox Equivalent Antioxidant Capacity of Tiger Nut Extracts. Bars $(n=3)$ expressed as means \pm SEM. Means within treatments without a common letter ${ }^{(a b c)}$ differ significantly at $\mathrm{p} \leq 0.05$. Abbreviations: TE-trolox equivalents, TRWA-tiger nut raw extracted with water, TRWM-tiger nut raw extracted with $80 \%$ methanol, TRA-Tiger nut roasted extracted with water, TRM - tiger nut roasted extracted with $80 \%$ methanol.

Table 1 and Table 2 show carbohydrate and lipid metabolizing enzyme inhibition by tiger nut extracts. The Western diet is of growing concern to researchers, as it contains a high amount of carbohydrates and fats; which contribute heavily to the pathogenesis of obesity and diabetes. Lipase and $\alpha$-amylase are enzymes that aid in the metabolism of fats (lipase) and carbohydrates ( $\alpha$-amylase). Inhibition of the aforementioned enzymes could lead to the prevention of diabetes and obesity. In aqueous extracts, processing had no effect on the inhibition of $\alpha$-amylase activity. Processing of tiger nut samples significantly ( $\mathrm{p} \leq 0.05)$ increased the $\alpha$-amylase inhibitory potential of tiger nut tubers compared to raw in methanolic extracts. Processing significantly $(\mathrm{p} \leq 0.05)$ increased lipase inhibitory potential in both aqueous and methanolic extracts, while aqueous extracts for both raw and roasted tubers inhibited significantly $(\mathrm{p} \leq 0.05)$ more lipase, compared to their methanolic counterparts. 
Table 1. $\alpha$-amylase inhibition by tiger nut extracts.

\begin{tabular}{cc}
\hline Tiger Nut Extracts & Percent $\alpha$-Amylase Inhibition \\
\hline TRWA & $75.79 \pm 0.74^{\mathrm{a}}$ \\
TRWM & $10.33 \pm 0.18^{\mathrm{c}}$ \\
TRA & $80.88 \pm 0.40^{\mathrm{a}}$ \\
TRM & $23.6 \pm 5.04^{\mathrm{b}}$ \\
\hline
\end{tabular}

Table 2. Lipase inhibition by tiger nut extracts.

\begin{tabular}{cc}
\hline Tiger Nut Extracts & Percent Lipase Inhibition \\
\hline TRWA & $74.61 \pm 2.33^{\mathrm{b}}$ \\
TRWM & $7.44 \pm 0.63^{\mathrm{d}}$ \\
TRA & $89.6 \pm 1.36^{\mathrm{a}}$ \\
TRM & $50.12 \pm 2.63^{\mathrm{c}}$ \\
\hline
\end{tabular}

Bars $(n=3)$ expressed as means \pm SEM. Means within treatments without a common letter ${ }^{(a b c)}$ differ significantly at $\mathrm{p} \leq 0.05$. Abbreviations: TRWA-tiger nut raw extracted with water, TRWM-tiger nut raw extracted with $80 \%$ methanol, TRA-Tiger nut roasted extracted with water, TRM-tiger nut roasted extracted with $80 \%$ methanol. Columns $(n=3)$ expressed as means \pm SEM. Means within treatments without a common letter ${ }^{(a b c)}$ differ significantly at $\mathrm{p} \leq 0.05$.

\section{Discussion}

TPC, TFC, DPPH, FRAP and TEAC were evaluated in various extractions oftiger nut tuber. Raw and roasted tubers were extracted with $80 \%$ methanol and water. In the present study, processing had an effect on phytochemical content and enzyme inhibition. The present results could relate to results by Chukwuma and others who showed processing effects on the phytochemical composition of tiger nut. The authors found that roasting decreased the concentrations of several phytochemicals in tiger nut tuber, including alkaloids, saponins and tannins [9].

In the present study, aqueous extracts of tiger nut had significantly higher TPC and TFC compared to methanolic. In a comparison by Sanchez-Zapata and others, tiger nut tubers contained a higher percent moisture compared to botanical nuts [8] [26]. This may account for the increased water-soluble phenolics and flavonoids in tiger nut tubers and might also account the increased $\alpha$-amylase and lipase inhibitory potential of aqueous extracts in the present study.

When comparing TPC of tiger nut, results from the present study agree with findings from Bilikis and Olanrewaju, where roasted tiger nut extracted with methanol had a significantly higher TPC compared to its dry (air-dried) and raw counterparts [27]. On the contrary, results from the present study showed that neither processing nor extraction solvent had an effect on DPPH radical scavenging ability of tiger nuts; but findings from Bilikis and Olanrewaju found that roasted tiger nut scavenged the radical more effectively than raw or dry tubers [27].

Researchers, Badejo and others, evaluated the effect of processing (germinat- 
ing, roasting) on the ABTS radical scavenging ability of tiger nuts. Similar to TEAC results in the present study, processing had no effect on the ABTS scavenging ability of tiger nuts in the study by [28].

A study by Chukwuma and others suggests tiger nut's ability to lower blood glucose levels. In the study, various levels of aqueous tiger nut extract were administered to rats; results from the study showed an indirectly proportional relationship between levels of tiger nut extract administered and blood glucose levels [9]. Results from the present study support other studies showing the anti-diabetic effect of tiger nut as tiger nut tubers extracted with water inhibited the $\alpha$-amylase enzyme more effectively than their methanolic counterparts.

A study conducted by Adekanmi and others determined that tiger nuts subjected to various processing methods still contained some level of tannins, most of which are water-soluble [29]. Tannins have been suggested to have an effect (inhibit) on various digestive enzymes, including lipase [30]. This aligns with results from the present study, which suggests that raw and roasted tiger nuts extracted with water had a significantly higher lipase and $\alpha$-amylase inhibition, compared to methanol extracts.

\section{Conclusions}

Though there are a number of products containing tubers on the market, very few utilize tiger nut tubers as an ingredient. The results of the study suggest that tiger nut extracts may benefit consumers by improving their antioxidant status and inhibiting carbohydrate and lipid metabolizing enzymes, possibly leading to the prevention of chronic disease.

Though the present study compares aqueous and methanolic extractions of tiger nut, ethanolic extracts were not taken into account. In further studies, the antioxidant capacity of tiger nut could be further explored by determining oxygen radical absorbance capacity (ORAC) and nitic oxide radical scavenging (NORS). Based on results from $\alpha$-amylase and lipase inhibition, in-vitro studies using a cell culture model could also be conducted to further determine the possible anti-diabetic and anti-obesity effects of tiger nut extracts.

\section{Conflicts of Interest}

The authors declare no conflicts of interest regarding the publication of this paper.

\section{References}

[1] Valko, M., Rhodes, C., Moncol, J., Izakovic, M.M. and Mazur, M. (2006) Free Radicals, Metals and Antioxidants in Oxidative Stress-Induced Cancer. Chemico-Biological Interactions, 160, 1-40. https://doi.org/10.1016/j.cbi.2005.12.009

[2] Baynes, J.W. (1991) Role of Oxidative Stress in Development of Complications in Diabetes. Diabetes, 40, 405-412. https://doi.org/10.2337/diab.40.4.405

[3] Furukawa, S., Fujita, T., Shimabukuro, M., Iwaki, M., Yamada, Y., Nakajima, Y., Shimomura, I., et al. (2017) Increased Oxidative Stress in Obesity and Its Impact on 
Metabolic Syndrome. The Journal of Clinical Investigation, 114, 1752-1761. https://doi.org/10.1172/JCI21625

[4] Gordon, M.H. (1990) The Mechanism of Antioxidant Action in Vitro. In: Hudson, B.J.F., Ed., Food Antioxidants, Springer, Berlin, 1-18. https://doi.org/10.1007/978-94-009-0753-9_1

[5] Zhang, Y.J., Gan, R.Y., Li, S., Zhou, Y., Li, A.N., Xu, D.P. and Li, H.B. (2015) Antioxidant Phytochemicals for the Prevention and Treatment of Chronic Diseases. Molecules, 20, 21138-21156. https://doi.org/10.3390/molecules201219753

[6] Chandrasekara, A. and Josheph Kumar, T. (2016) Roots and Tuber Crops as Functional Foods: A Review on Phytochemical Constituents and Their Potential Health Benefits. International Journal of Food Science, 2016, Article ID: 3631647. https://doi.org/10.1155/2016/3631647

[7] USDA NAL (2015). https://fnic.nal.usda.gov/food-composition

[8] Sánchez-Zapata, E., Fernández-López, J. and Angel Pérez-Alvarez, J. (2012) Tiger Nut (Cyperus esculentus) Commercialization: Health Aspects, Composition, Properties, and Food Applications. Comprehensive Reviews in Food Science and Food Safety, 11, 366-377. https://doi.org/10.1111/j.1541-4337.2012.00190.x

[9] Chukwuma, E.R., Obioma, N. and Christopher, O.I. (2010) The Phytochemical Composition and Some Biochemical Effects of Nigerian Tigernut (Cyperus esculentus L.) Tuber. Pakistan Journal of Nutrition, 9, 709-715. https://doi.org/10.3923/pjn.2010.709.715

[10] Adejuyitan, J.A., Otunola, E.T., Akande, E.A., Bolarinwa, I.F. and Oladokun, F.M. (2009) Some Physicochemical Properties of Flour Obtained from Fermentation of Tiger Nut (Cyperus esculentus) Sourced from a Market in Ogbomoso, Nigeria. African Journal of Food Science, 3, 51-55.

[11] Koubaa, M., Barba, F.J., Mhemdi, H., Grimi, N., Koubaa, W. and Vorobiev, E. (2015) Gas Assisted Mechanical Expression (GAME) as a Promising Technology for Oil and Phenolic Compound Recovery from Tiger Nuts. Innovative Food Science \& Emerging Technologies, 32, 172-180. https://doi.org/10.1016/j.ifset.2015.09.019

[12] Carrera-Bastos, P., Fontes-Villalba, M., O’Keefe, J.H., Lindeberg, S. and Cordain, L. (2011) The Wester Diet and Lifestyle and Diseases of Civilization. Research Reports in Clinical Cardiology, 2, 15-35. https://doi.org/10.2147/RRCC.S16919

[13] Petra, S., et al. (2009) Screening of Selected Food and Medicinal Plant Extracts for Pancreatic Lipase Inhibition. Phytotherapy Research: An International Journal Devoted to Pharmacological and Toxicological Evaluation of Natural Product Derivatives, 23, 874-877. https://doi.org/10.1002/ptr.2718

[14] Drent, M.L. (1993) Lipase Inhibition: A Novel Concept in the Treatment of Obesity. International Journal of Obesity and Related Metabolic Disorders, 17, 241-244.

[15] Kenjiro, T., et al. (2006) Inhibition of $\alpha$-Glucosidase and $\alpha$-Amylase by Flavonoids. Journal of Nutritional Science and Vitaminology, 52, 149-153. https://doi.org/10.3177/jnsv.52.149

[16] Mahadita, G.W., Jawi, M. and Suastika, K. (2016) Purple Sweet Potato Tuber Extract Lowers Malondialdehyde and Improves Glycemic Control in Subjects with Type 2 Diabetes Mellitus.

[17] Unuofin, J.O., Otunola, G.A. and Afolayan, A.J. (2018) In Vitro $\alpha$-Amylase, $\alpha$-Glucosidase, Lipase Inhibitory and Cytotoxic Activities of Tuber Extracts of Kedrostis africana (L.) Cogn. Heliyon, 4, e00810. https://doi.org/10.1016/j.heliyon.2018.e00810

[18] Dewanto, V., Wu, X., Adom, K.K. and Liu, R.H. (2002) Thermal Processing En- 
hances the Nutritional Value of Tomatoes by Increasing Total Antioxidant Activity. Journal of Agricultural and Food Chemistry, 50, 3010-3014. https://doi.org/10.1021/jf0115589

[19] Li, W., Pickard, M.D. and Beta, T. (2007) Effect of Thermal Processing on Antioxidant Properties of Purple Wheat Bran. Food Chemistry, 104, 1080-1086. https://doi.org/10.1016/j.foodchem.2007.01.024

[20] Shackelford, L., Mentreddy, S.R., Cedric, S., et al. (2009) Determination of Total Phenolics, Flavonoids and Antioxidant and Chemopreventive Potential of Basil (Ocimum basilicum L. and Ocimum tenuiflorum L.). International Journal of Cancer Research, 5, 130-143. https://doi.org/10.3923/ijcr.2009.130.143

[21] Benzie Iris, F.F. and Strain, J.J. (1999) Ferric Reducing/Antioxidant Power Assay: Direct Measure of Total Antioxidant Activity of Biological Fluids and Modified Version for Simultaneous Measurement of Total Antioxidant Power and Ascorbic Acid Concentration. Methods in Enzymology, 299, 15-27. https://doi.org/10.1016/S0076-6879(99)99005-5

[22] Miller, N.J. and Rice-Evans, C.A. (1997) Factors Influencing the Antioxidant Activity Determined by the $\mathrm{ABTS}^{+}$Radical Cation Assay. Free Radical Research, 26, 195-199. https://doi.org/10.3109/10715769709097799

[23] Mosmuller, E.W.J., et al. (1992) A New Spectrophotometric Method for the Detection of Lipase Activity Using 2, 4-Dinitrophenyl Butyrate as a Substrate. Biocatalysis, 5, 279-287. https://doi.org/10.3109/10242429209014874

[24] Apostolidis, E., et al. (2007) Inhibitory Potential of Herb, Fruit, and FungalEnriched Cheese against Key Enzymes Linked to Type 2 Diabetes and Hypertension. Innovative Food Science \& Emerging Technologies, 8, 46-54. https://doi.org/10.1016/j.ifset.2006.06.001

[25] Brand-Williams, W., Cuvelier, M.E. and Berset, C.L.W.T. (1995) Use of a Free Radical Method to Evaluate Antioxidant Activity. LWT_Food Science and Technology, 28, 25-30. https://doi.org/10.1016/S0023-6438(95)80008-5

[26] Alegría-Torán, A. and Farré-Rovira, R. (2003) Horchata y salud: Aspectosnutricionales y dietéticos. In: Fundación Valenciana de Estudios Avanzados, Ed., Jornada Chufa y Horchata: Tradición y Salud, Consellería de Agricultura, Pesca y Alimentación, Valencia, 55-70.

[27] Bilikis, A. and Olanrewaju, A. (2015) Chemical Compositions, Antioxidant Capacity of Tigernut (Cyperus esculentus) and Potential Health Benefits. European Scientific Journal, 2015, 217-224.

[28] Badejo, A.A., Damilare, A. and Ojuade, T.D. (2014) Processing Effects on the Antioxidant Activities of Beverage Blends Developed from Cyperus esculentus, Hibiscus sabdariffa, and Moringa oleifera Extracts. Preventive Nutrition and Food Science, 19, 227. https://doi.org/10.3746/pnf.2014.19.3.227

[29] Adekanmi, O.K., Oluwatooyin, O.F., Yemisi, A.A. and Yemisi, A.A. (2009) Influence of Processing Techniques on the Nutrients and Antinutrients of Tigernut ( $C y$ perus esculentus L.). World Journal of Dairy \& Food Sciences, 4, 88-93.

[30] Griffiths, D.W. (1979) The Inhibition of Enzymes by Extracts of Field Beans, Vivizfeba. Journal of Agricultural and Food Chemistry, 28, 459-461. 